\title{
LEPROSY: INFECTIOUS DISEASE MIMICKING RHEUMATIC DISEASES
}

Francisco Helialdo Sousa de Oliveira Filho', Priscila Dourado Evangelista ${ }^{1, \star}$, Priscila Garcia Câmara Cabral Tavares ${ }^{1}$, Luiz Valério Costa Vasconcelos ${ }^{2}$, Marina Pinto Rocha ${ }^{2}$, Ana Carolina Cavalcante Mendonça ${ }^{2}$, Adah Sophia Rodrigues Vieira ${ }^{2}$, Ana Natália Vasconcelos Arcanjo², Francisca Adna Almeida De Oliveira², Gabriela Oliveira Muniz² ${ }^{2}$ Yasmine Portela Velez², Rodrigo Barbosa De Azevedo ${ }^{1}$

1.Hospital Geral Dr. César Cals, Fortaleza (CE), Brazil; 2.Universidade de Fortaleza, Fortaleza (CE), Brazil.

*Corresponding author: prisdourado@yahoo.com.br

\section{BACKGROUND}

Leprosy is a chronic granulomatous infectious disease caused by Mycobacterium leprae. Neurological and rheumatological manifestations can occur. This pathology is capable of mimicking acute or chronic polyarthritis. The use of anti-TNF (tumor necrosis factor), which is an immunomodulator of the immune response, used to treat rheumatic diseases, may increase the risk of opportunistic infections by suppressing endogenous TNF-, an important cytokine for granuloma formation. Thus, the risk of latent tuberculosis and other infections, such as leprosy, needs to be assessed before starting treatment.

\section{CASE R PORT}

Female, 41 years old, in childhood was diagnosed with psoriatic arthritis. In 2018, she started presenting with asymmetric arthritis and dactylitis (rheumatoid factor and anti-CCP negative, HLA-B27 not detectable, PPD 0 mm, no contact with people with tuberculosis and chest X-ray unchanged). There was partial improvement of arthritis with the use of methotrexate. In April 2019, association of methotrexate with adalimumab was performed and methotrexate was discontinued due to elevated transaminases. After 4 months of adalimumab use, she presented with rash, improving after corticosteroid use. In August 2019, secukinumab was started, presenting again with hyperemic lesions on the lower limbs, with no improvement with prednisone $1 \mathrm{mg} / \mathrm{kg}$. In February 2020 , she began presenting with lower limb edema, pain and paresthesia. There was significant worsening of the lesions, extending to the rest of the body, denying pruritus and desquamation. The patient presented with an infiltrate in the nose and left ear canal associated with fever of $38-38.5^{\circ} \mathrm{C}$, worse at night. A skin biopsy was performed on the face and right lower limb, which was compatible with multibacillary leprosy. Treatment was started with rifampicin, dapsone and clofazimine. patient in regression of skin lesions, reduction of extension, hyperemia and edema.

\section{CONCLUSION}

Leprosy is able to mimic the clinical picture of psoriatic arthritis, with dactylitis and lesions suggestive of psoriasis. In most parts of the world, leprosy is almost extinct, but cases can arise under immunosuppression. The use of TNF- $\alpha$ predisposition to infections with confronting organisms. In leprosy, an absence of IL-17 activity can be observed, which may have caused a worsening of the condition after the use of secukinumab. In both occasions in which immunobiological were used, the patient evolved with a leprosy reaction, showing the importance of investigating this pathology before starting these drugs.

\section{KEYWORDS}

Leprosy, Infectious disease, TNF- $\alpha$. 